\title{
Effect of Cholecalciferol in Food Allergy Mouse Model Is Associated with Decrease of $\mathrm{CD69}^{+} \mathrm{CD4}^{+} \mathrm{T}$ Cells
}

\author{
Ece Zaim, Shigeru Ashino*, Toshifumi OsaKa, Naoko YanagisaWA and Junji Yagi \\ Department of Microbiology and Immunology, Tokyo Women's Medical University, \\ 8-1 Kawada-cho, Shinjuku-ku, Tokyo 162-8666, Japan
}

(Received November 1, 2018)

\begin{abstract}
Summary Food allergy prevalence is increasing all over the world. Recent epidemiologic studies have shown the link between vitamin $\mathrm{D}_{3}$ insufficiency and food allergy occurrence. In this study, we investigated the effect of supplementation with cholecalciferol, a widely used form of vitamin $\mathrm{D}_{3}$, on food allergy using an experimental mouse model. In wild-type $\mathrm{BALB} / \mathrm{c}$ mice which were sensitized and challenged with an experimental allergen, ovalbumin, a clinical symptom of food allergy, diarrhea, was significantly induced with the elevation of immunoglobulin $\mathrm{E}$ level and the increases of $\mathrm{T}$ helper 2 cytokine productions, such as interleukin-4, -5 , and $-13(p<0.05)$, whereas no change in T helper 1 cytokine production, such as interferon- $\gamma$, was observed. It was also found that cell population of $\mathrm{CD} 69^{+} \mathrm{CD} 4^{+}$ $\mathrm{T}$ cells was increased slightly in spleen and significantly in the mesenteric lymphnode with the diarrheal symptom $(p<0.05)$. Treatment of cholecalciferol reduced the allergic diarrhea $(p<0.05)$ with the decreasing tendency of $\mathrm{CD} 69^{+} \mathrm{CD} 4^{+} \mathrm{T}$ cells, suggesting that the cell population might be associated with the attenuating effect of cholecalciferol on diarrhea occurrence, although immunoglobulin E levels and cytokine productions were not significantly altered by the treatment of cholecalciferol. When given the mice anti-CD69 mAb treatment, significant improvement of allergic diarrhea symptom was observed $(p<0.05)$, accompanying the decrease of $\mathrm{CD}_{6} 9^{+} \mathrm{CD} 4^{+} \mathrm{T}$ cells which suggested the contribution of these cells to the diarrhea symptom. Taken together, we suggest that administration of cholecalciferol might be useful to suppress symptomatic food allergy in association with the decrease of $\mathrm{CD} 69^{+} \mathrm{CD} 4^{+} \mathrm{T}$ cells.
\end{abstract}

Key Words food allergy, ovalbumin, vitamin $\mathrm{D}_{3}$, diarrhea, CD69

The prevalence of allergic diseases including asthma, atopic dermatitis and food allergy has been increasing all over the world. Food allergy incidence was reported to exist up to $8 \%$ of children and $4 \%$ of adults to one or more food antigens $(1,2)$, and children with food allergies are found to be 2 to 4 times more likely to suffer from other atopic diseases $(1,2)$. Current standard treatment of food allergy consists of antigen avoidance as preventive care and emergency treatments as a reaction-based treatment. Oral immunotherapy research offers a promising treatment, however it has had limited success considering safety and long-term efficacy (3).

Vitamin $\mathrm{D}_{3}$ is known to be involved not only in mineral and skeletal homeostasis but also in immune-system regulation as well as in maintaining mucosal barrier (4). Recent epidemiologic studies have shown that vitamin $\mathrm{D}_{3}$ insufficiency is a risk factor for food allergy (1). There is suggestive prevalence in studies showing a link between vitamin $D_{3}$, sensitization to food allergen

\footnotetext{
${ }^{*}$ To whom correspondence should be addressed.

E-mail: ashino.shigeru@twmu.ac.jp

Abbreviations: Alum, aluminum hydroxide; ELISA, enzymelinked immunosorbent assay; IFN, interferon; IgE, immunoglobulin E; IgG, immunoglobulin G; IL, interleukin; mAb, monoclonal antibody; MLN, mesenteric lymph node; OVA, ovalbumin; Th, T helper.
}

and food allergy (5-7). In addition, there are several clinical trials evaluating vitamin $\mathrm{D}_{3}$ supplementation for allergic diseases including food allergy $(8,9)$. However the effect of vitamin $\mathrm{D}_{3}$ on food allergy has not been fully elucidated. In the current study, we investigated whether cholecalciferol, a widely used supplement form of vitamin $\mathrm{D}_{3}(10)$, has a promising effect on the treatment of food allergy in a mouse model. The results in the present study may provide the possibility of supplementation to the management of a symptom of food allergy.

\section{MATERIALS AND METHODS}

Animals. Five-weeks old female wild-type BALB/c mice were purchased from Charles River Company (Hino Branch, Tokyo, Japan). Mice were housed in the animal facility at the Department of Microbiology and Immunology, Tokyo Women's Medical University (TWMU). During the entire period of experiments, mice were ad libitum given water and pellet diet (LABO MR stock, Nosan Corporation, Yokohama, Japan) which the diet formula was shown in Supplemental Online Material, Table S1. The study was approved by the Ethical Review Committee of Animal Experiments, TWMU, in accordance with the Guide for the Care and Use of the Laboratory Animals (Approval number: AE18-059). 


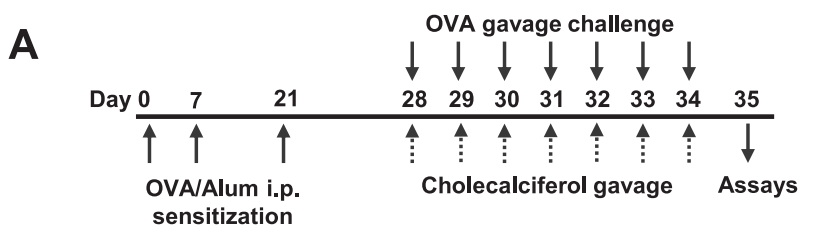

B
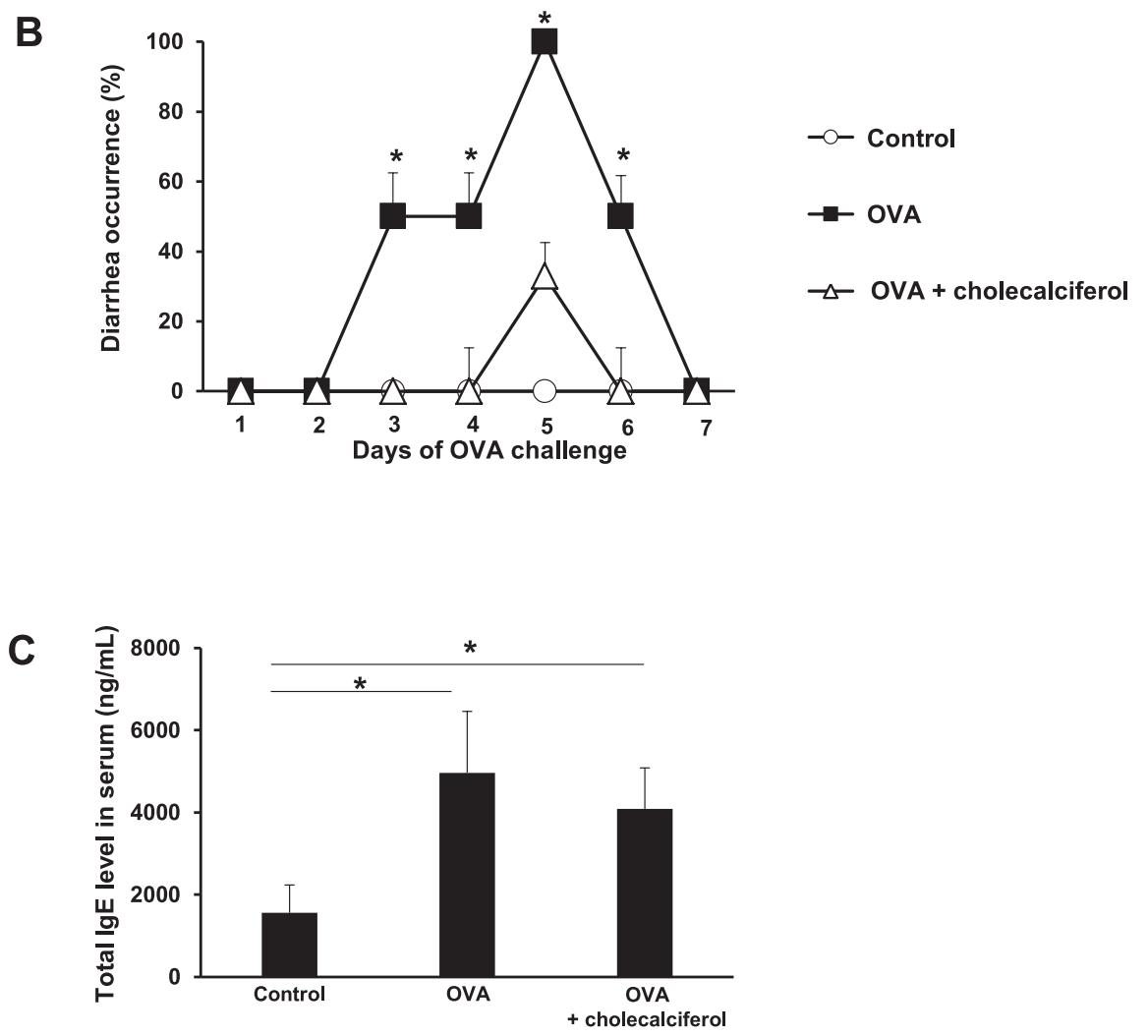

Fig. 1. Effect of cholecalciferol administration in food allergy model. (A) Protocol of OVA sensitization, OVA challenge and cholecalciferol administration to mice. (B) Diarrhea occurrence during the $7 \mathrm{~d}$ of challenge was monitored in mice which were not sensitized but challenged with OVA (control group, $n=5$ ), sensitized and challenged with OVA (OVA group, $n=5$ ), or sensitized and challenged with OVA plus treatment with cholecalciferol (OVA+cholecalciferol group, $n=5)$. (C) Total IgE levels in sera $24 \mathrm{~h}$ after the final OVA challenge were measured by ELISA. The data for each group were expressed as means \pm SE. ${ }^{*} p<0.05$, OVA-group compared with control group and OVA + cholecalciferol group compared with control group (Mann-Whitney $U$ test).

Food allergy mouse model. Allergen sensitization to mice was performed by intraperitoneal injection of $50 \mu \mathrm{g}$ of ovalbumin (OVA) (Sigma-Aldrich, Burlington, MA, USA) with $2 \mathrm{mg}$ of aluminum hydroxide (Alum) in $200 \mu \mathrm{L}$ of PBS, on days 0, 7 and 21. Allergen challenge was performed by oral gavage inoculation of $50 \mathrm{mg}$ of OVA in $200 \mu \mathrm{L}$ of PBS administered to mice for seven consecutive days from day 28 to day $34(n=5)$. Control mice $(n=5)$ were those which were not sensitized with OVA and Alum. The food allergy reaction was diagnosed by the clinical sign of diarrhea which was a typical symptom of an experimental food allergy model. The diarrhea was assessed by visually monitoring feces of mice within 60 min after each OVA challenge. Mice showing profuse liquid form feces were recorded as diarrhea-positive as shown in Supplemental Online Mate- rial, Fig. S1. The number of diarrhea positive mice was counted after each OVA challenge, and the percentage of diarrhea occurrence was calculated by dividing number of diarrhea-positive mice by number of mice per group. Mice were sacrificed on day 35 by intraperitoneal injection of $75 \mathrm{mg} / \mathrm{kg}$ pentobarbital with $10 \mathrm{mg} / \mathrm{kg}$ xylazine. Sera, spleens and mesenteric lymph nodes (MLNs) were collected for further analyses.

Cholecalciferol and anti-CD69 antibody treatments in food allergy model mice. Cholecalciferol treatment was undertaken by oral administration of $0.2 \mu \mathrm{g}$ cholecalciferol together with OVA challenge in $200 \mu \mathrm{L}$ of PBS $(n=5)$. The effect of cholecalciferol was investigated by monitoring of diarrhea occurrence. Mice were sacrificed on day 35, and cytokine levels were measured in the culture supernatants of $4 \times 10^{5}$ cells derived from 

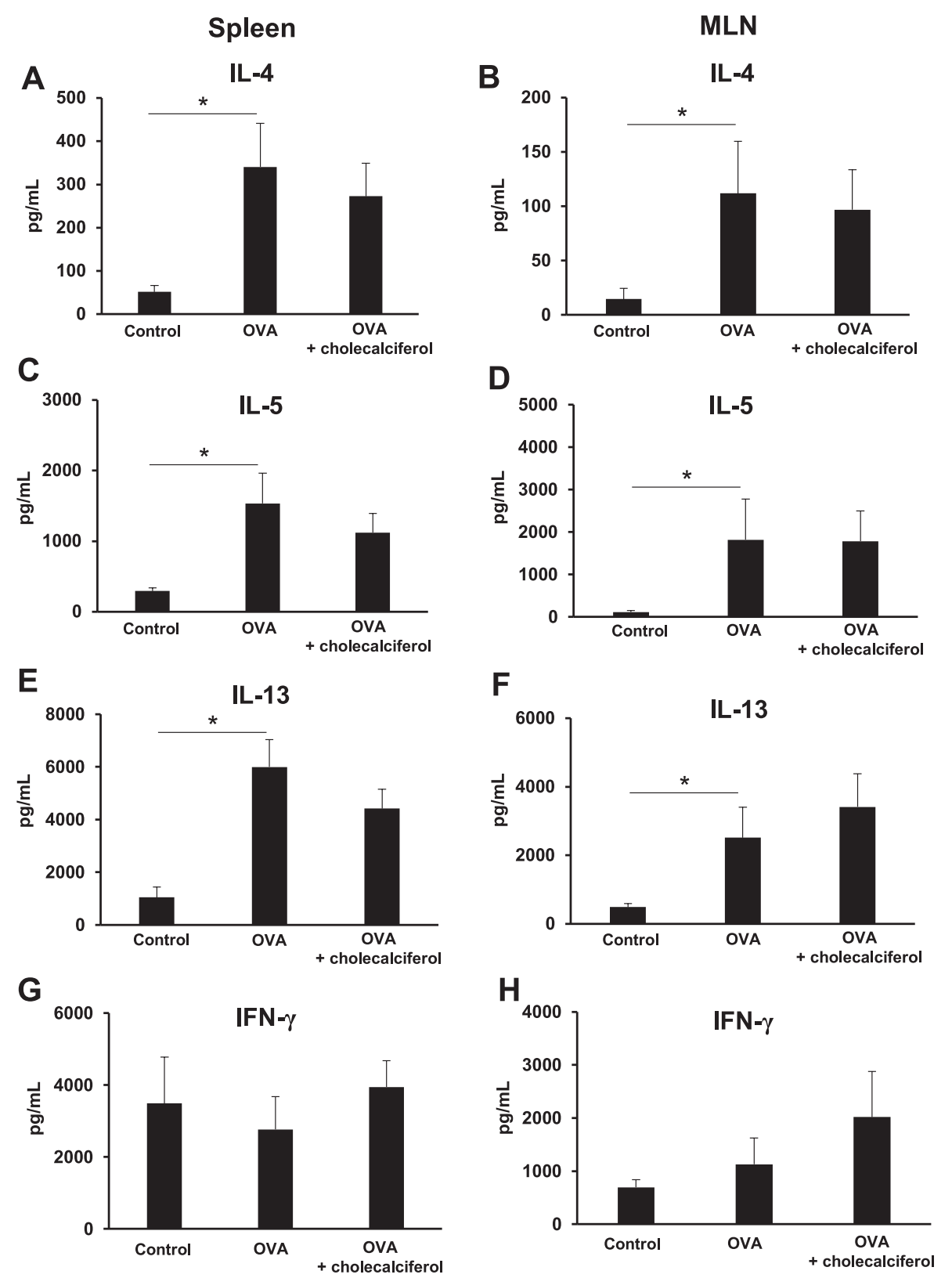

Fig. 2. Effect of oral cholecalciferol administration on cytokine productions in spleen and MLN. Experiments were performed as in Fig. 1A. Twenty-four hours after final OVA challenge, spleen and MLN derived cells were collected from the mice which were not sensitized but challenged with OVA (control group, $n=5$ ), sensitized and challenged with OVA (OVA group, $n=5$ ), or sensitized and challenged with OVA plus treatment with cholecalciferol (OVA+cholecalciferol group, $n=5$ ), and stimulated with OVA in vitro. Cytokine levels in the culture supernatants were measured by ELISAs. The data for each group were expressed as means \pm SE. ${ }^{*} p<0.05$ (Mann-Whitney $U$ test).

spleens and MLNs in $200 \mu \mathrm{L}$ of complete-RPMI medium per well incubated with re-stimulation of OVA $(100 \mu \mathrm{g} /$ $\mathrm{mL})$ at $37^{\circ} \mathrm{C}$ in $5 \% \mathrm{CO}_{2}$ for $5 \mathrm{~d}$.

In another experiment, $50 \mu \mathrm{g}$ of anti-CD69 monoclonal antibody (mAb, clone H1.2F3, BioLegend, San Diego, CA, USA) was administered by intraperitoneal injection in $200 \mu \mathrm{L}$ of PBS on day 27 as the first treatment, and at 3-4 h prior to OVA challenge on day 28 as the second treatment $(n=5)$. Fifty micrograms of hamster immunoglobulin G (IgG) (BioLegend) was used as control IgG corresponding to the IgG of anti-CD69 $\mathrm{mAb}$ $(n=5)$. The effect of anti-CD69 antibody was investigated by monitoring of diarrhea occurrence and mea- surements of cytokine levels in the culture supernatants of cells derived from spleens and MLNs, under the same cell culture condition as the cholecalciferol treatment experiment.

Enzyme-linked immunosorbent assay (ELISA). ELISA (eBioscience, San Diego, CA, USA) was used to measure the levels of cytokines, including T helper 2 (Th2) cytokine such as interleukin (IL)-4, IL-5, IL-13, and T helper 1 (Th1) cytokine, such as interferon (IFN)- $\gamma$, in cell culture supernatants of spleen and MLN cells. Total immunoglobulin E (IgE) levels in sera collected $24 \mathrm{~h}$ after the final OVA challenge were measured by ELISA (eBioscience). 

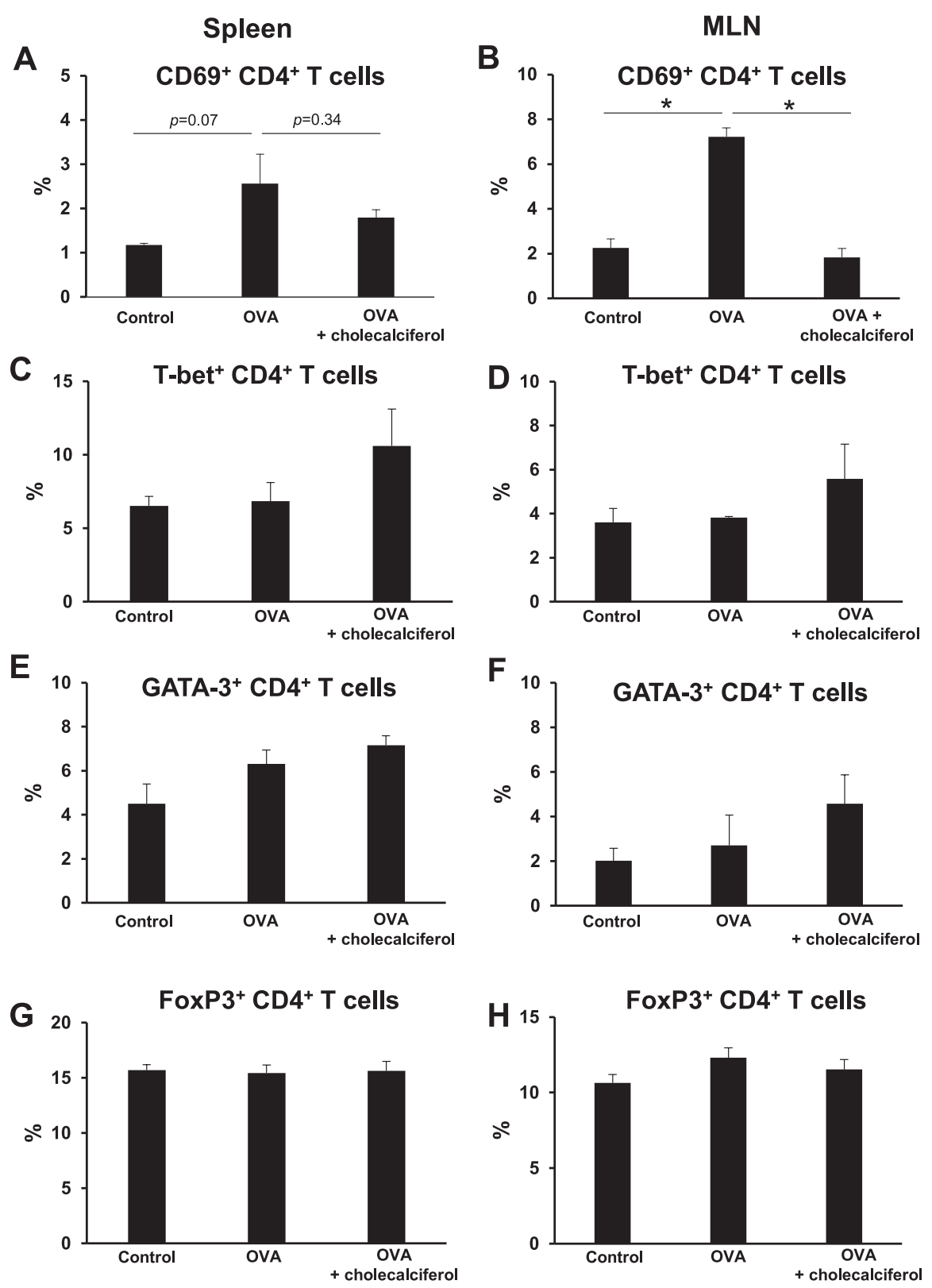

Fig. 3. Effect of cholecalciferol administration on $\mathrm{CD} 4^{+} \mathrm{T}$ cell population in spleen and MLN. Experiments were performed as in Fig. 1A. Twenty-four hours after final OVA challenge, spleen and MLN derived cells were collected from the mice which were not sensitized but challenged with OVA (control group, $n=5$ ), sensitized and challenged with OVA (OVA group, $n=5$ ), or sensitized and challenged with OVA plus treatment with cholecalciferol (OVA + cholecalciferol group, $n=5$ ), and stained with flow cytometry antibodies. Flow cytometry were carried out using FACSCalibur and the percentages of cell populations were calculated based on the data. The data for each group were expressed as means \pm SE. ${ }^{*} p<0.05$ (MannWhitney $U$ test).

Flow cytometry. Cell population analysis was performed by flow cytometry using FACSCalibur (BD Biosciences, San Diego, USA). PE-conjugated anti-CD69, FoxP3, GATA-3 and T-bet mAbs, and APC- or FITCconjugated anti-CD4 mAbs (BD Biosciences) were used. FoxP3, GATA-3 and T-bet staining were performed using staining kits (Thermo Fisher Scientific Co., Waltham, MA, USA). Flow cytometry data were analyzed by using the FlowJo software (FlowJo LLC, Ashland, OR, USA).

Statistical analysis. Statistical analyses were performed using Mann-Whitney $U$ test. $p$ value $<0.05$ was considered as statistically significant difference.

\section{RESULTS}

Effect of cholecalciferol administration on clinical sign of OVA-induced food allergy

The object of the study was to assess the effect of cholecalciferol on food allergy using an experimental model. In the current study, mice were non-sensitized but challenged with OVA (control group), sensitized and challenged with OVA (OVA group), or sensitized and challenged with OVA plus cholecalciferol treatment (OVA + cholecalciferol group) as shown in Fig. 1A. When given the challenges with OVA to mice for $7 \mathrm{~d}$, OVA 
A

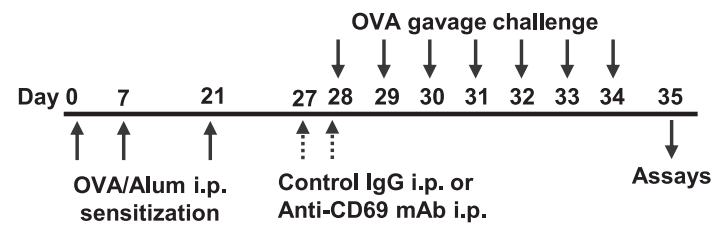

B
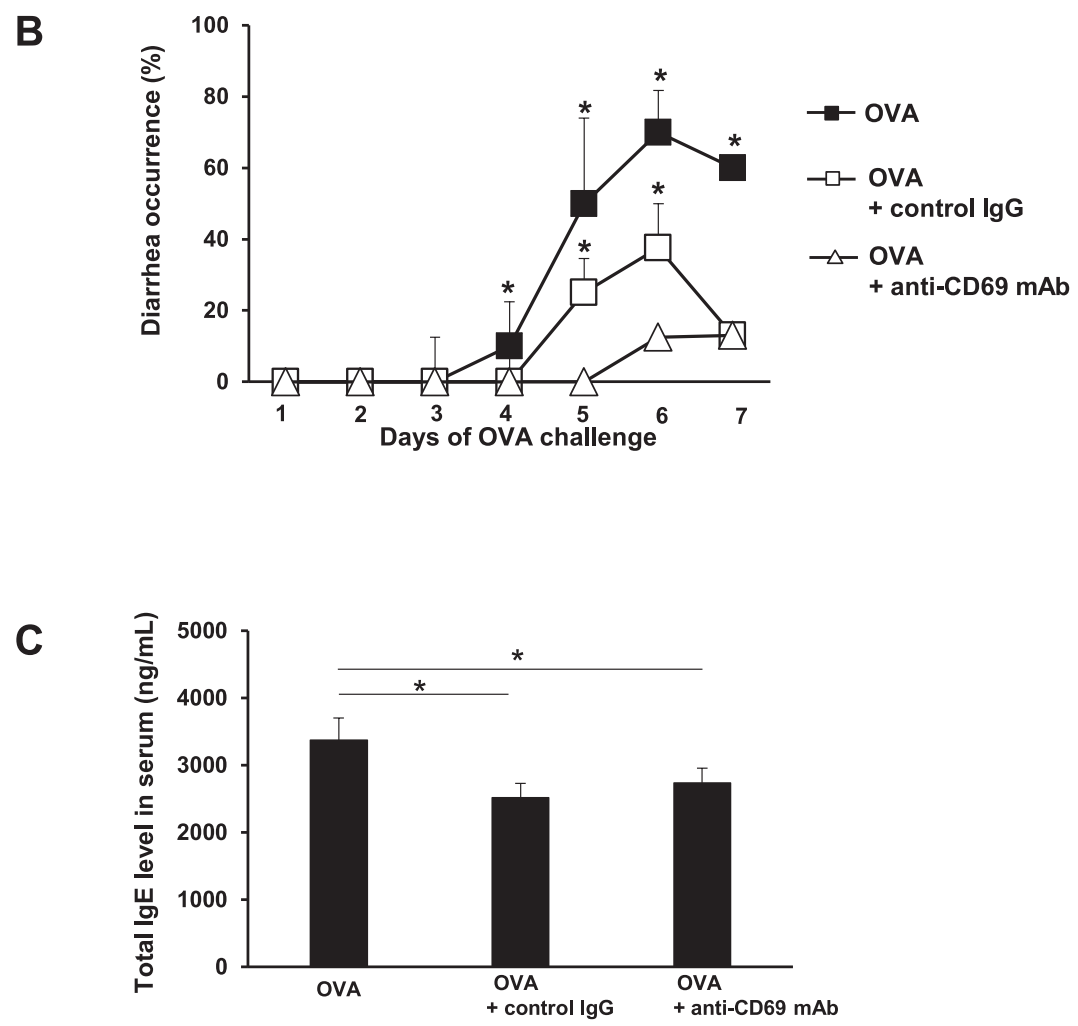

Fig. 4. Effect of anti-CD69 mAb treatment in food allergy model. (A) Protocol of OVA sensitization, OVA challenge and control IgG or anti-CD69 mAb treatment to mice. (B) Diarrhea occurrence during the $7 \mathrm{~d}$ of OVA challenge was monitored in mice which were challenged with OVA (OVA group, $n=5$ ), challenged with OVA plus treatment with control IgG (OVA+ control IgG group, $n=5$ ) or anti-CD69 mAb (OVA+anti-CD69 mAb group, $n=5)$. (C) Total IgE levels in sera $24 \mathrm{~h}$ after the final OVA challenge were measured by ELISA. The data for each group were expressed as means \pm SE. ${ }^{*} p<0.05$, OVA + anti-CD69 mAb group compared with OVA+ control-IgG group, and OVA+anti-CD69 mAb group compared with OVA group (Mann-Whitney $U$ test).

group developed a food allergic reaction, diarrhea, from days 3 to 6 . Treatment with cholecalciferol significantly decreased the percentage of diarrhea occurrence during the OVA challenges $(p<0.05$, diarrhea occurrence percentage of OVA group compared with OVA + cholecalciferol group, on days 3, 4, 5 and 6, respectively, Fig. 1B). Although diarrhea occurrence of $33 \%$ was observed on day 5 in OVA + cholecalciferol group, the percentage of diarrhea occurrence was significantly less than OVA group. Control group did not show signs of diarrhea during the entire $7 \mathrm{~d}$ of OVA challenge (Fig. 1B).

Effect of cholecalciferol administration on IgE production

OVA-sensitized and -challenged mice increased IgE level in sera compared to those of the control mice $(p<0.05$, OVA group compared with the control group, Fig. 1C). It was seemed that treatment of cholecalciferol slightly decreased total IgE levels to approximately $82 \%$ of that of OVA group, although the difference between the two groups was not statistically significant (Fig. 1C). Effect of cholecalciferol administration on cytokine productions in OVA-induced food allergy

Effects of cholecalciferol on cytokine productions were analyzed in the OVA-induced food allergy model. OVA group showed the increased cytokine productions of IL-4, IL-5, IL-13 in spleen and MLN, compared to those of control group ( $p<0.05$, control group compared with OVA group, Fig. 2 A-F), whereas production of IFN- $\gamma$ was not changed (Fig. 2 G, H). Although IL-4, IL-5 and IL-13 productions in spleen were slightly lower in OVA + cholecalciferol group approximately reduced to 80,73 and $74 \%$, respectively, compared to those of OVA group, the effects of cholecalciferol treatment on 

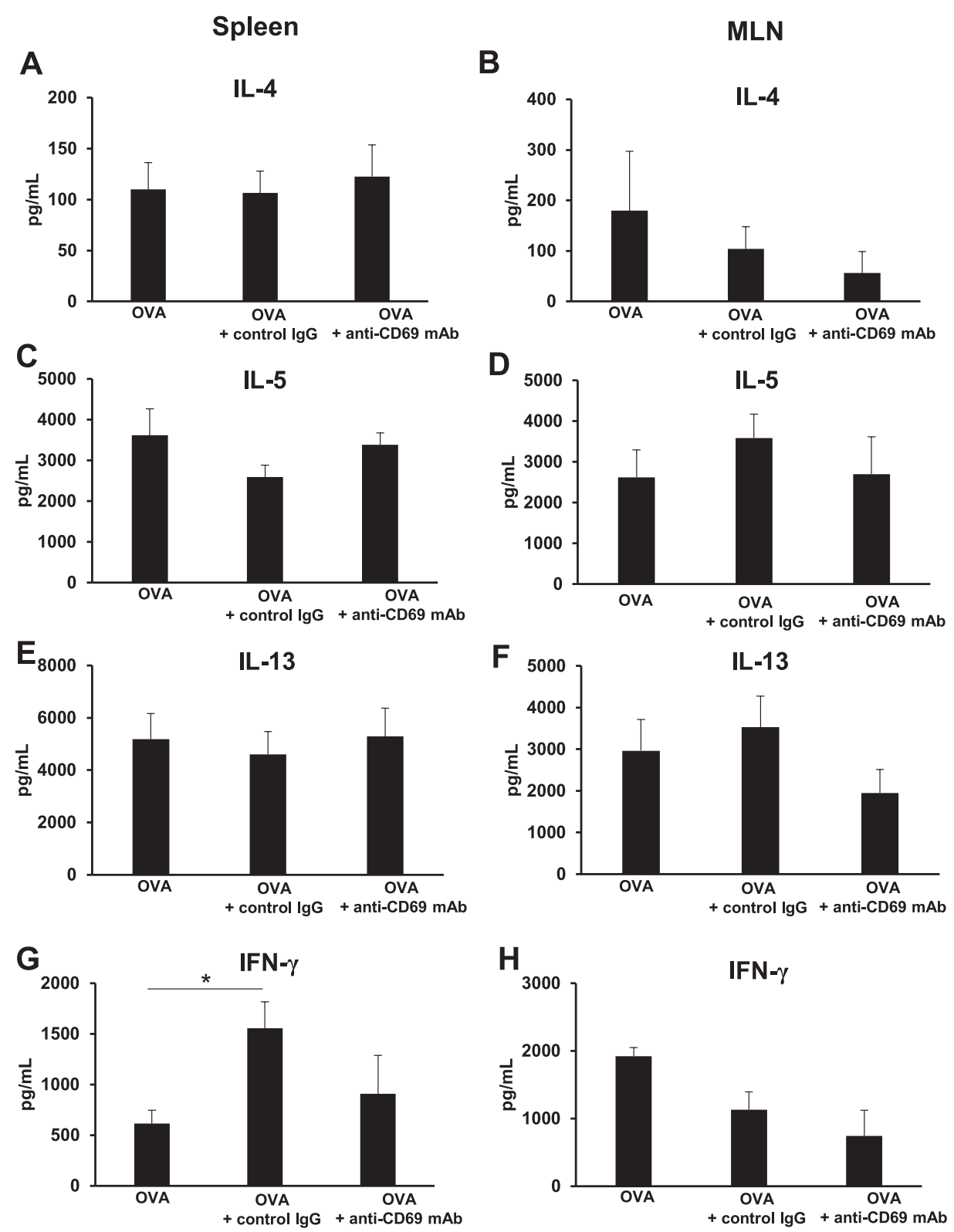

Fig. 5. Effect of anti-CD69 mAb treatment on cytokine productions in spleen and MLN. Experiments were performed as in Fig. 4A. Twenty-four hours after final OVA challenge, spleen or MLN derived cells were collected from the mice which were sensitized and challenged with OVA (OVA group, $n=5$ ), sensitized and challenged with OVA plus treatment with control IgG (OVA + control IgG group, $n=5)$ or anti-CD69 mAb (OVA+anti-CD69 mAb group, $n=5)$, and stimulated with OVA in vitro. Cytokine levels in the culture supernatants were measured by ELISAs. The data for each group were expressed as means \pm SE. ${ }^{*} p<0.05$ (Mann-Whitney $U$ test).

the cytokine productions were not statistically significant. In addition, cytokine productions in MLN were not altered by the treatment of cholecalciferol.

Effect of cholecalciferol administration on $\mathrm{CD}^{+} \mathrm{T}$ cell population in OVA-induced food allergy

The effect of cholecalciferol on $\mathrm{CD} 4^{+} \mathrm{T}$ cell population was investigated in the food allergy model. OVA group showed increasing tendency of $\mathrm{CD} 69^{+} \mathrm{CD} 4^{+} \mathrm{T}$ cells in spleen $(p=0.07$, control group compared with OVA group, Fig. 3A) and significantly increased the cell population in MLN $(p<0.05$, control group compared with OVA group, Fig. 3B). OVA+cholecalciferol group showed decreasing tendency of $\mathrm{CD} 69^{+} \mathrm{CD}^{+} \mathrm{T}$ cells in spleen ( $p=0.34$, OVA group compared with OVA + cho- lecalciferol group) and significantly decreased the cell population in MLN $(p<0.05$, OVA group compared with OVA + cholecalciferol group). Among three groups of control, OVA, and OVA+cholecalciferol, there were not significant differences on cell populations of T-bet ${ }^{+}$, GATA $-3^{+}$, or $\mathrm{FoxP}^{+} \mathrm{CD}^{+}{ }^{+} \mathrm{T}$ cells in the spleen and MLN (Fig. $3 \mathrm{C}-\mathrm{H})$.

Effect of anti-CD69 mAb treatment on clinical sign of OVAinduced food allergy

Since it was suggested that the administration of cholecalciferol was capable of decreasing the population of $\mathrm{CD} 69^{+} \mathrm{CD} 4^{+} \mathrm{T}$ cells with the reduction of food allergic reaction such as diarrhea, the cell population seemed to be involved in the regulation of diarrhea occurrence. 
Spleen

A

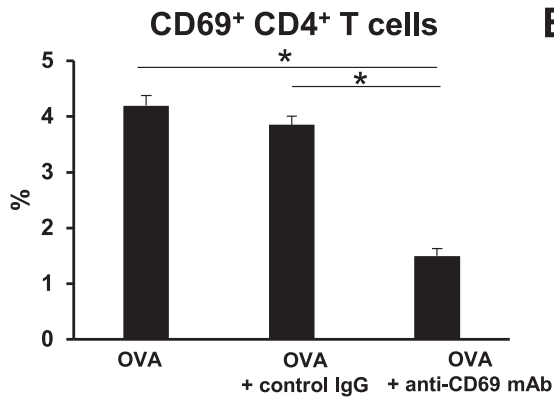

C

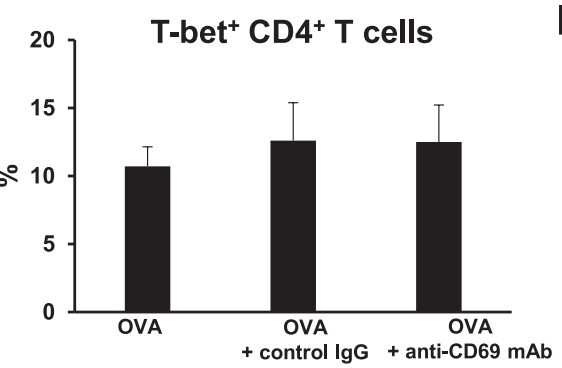

MLN
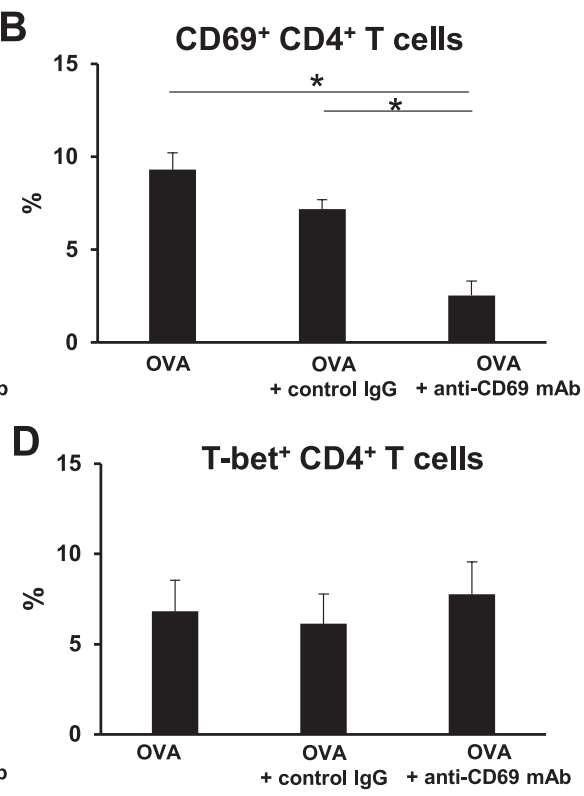

$\mathbf{F}$

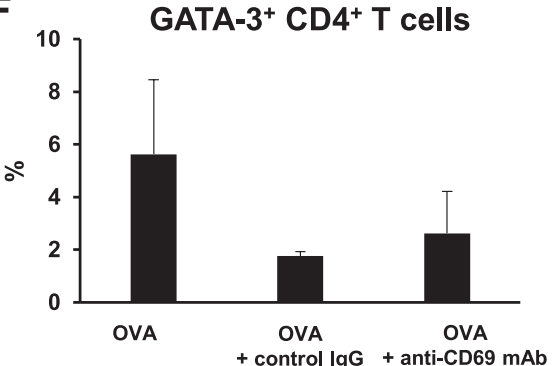

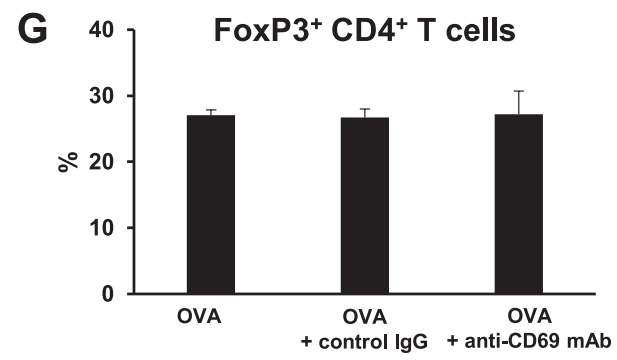

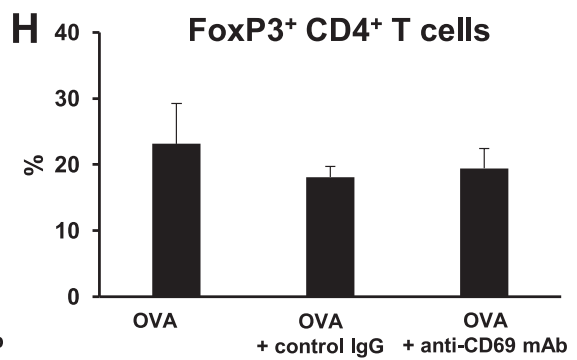

Fig. 6. Effect of anti-CD69 mAb treatment on $\mathrm{CD} 4^{+} \mathrm{T}$ cell population in spleen and MLN. Experiments were performed as in Fig. 4A. Twenty-four h after final OVA challenge, spleen and MLN derived cells were collected from the mice which were sensitized and challenged with OVA (OVA group, $n=5$ ), sensitized and challenged with OVA plus treatment with control IgG (OVA + control IgG group, $n=5$ ) or anti-CD69 mAb (OVA+ anti-CD69 mAb group, $n=5)$ and stained with flow cytometry antibodies. Flow cytometry were carried out using FACSCalibur and the percentages of cell populations were calculated based on the data. The data for each group were expressed as means \pm SE. ${ }^{*} p<0.05$ (Mann-Whitney $U$ test).

Therefore, to confirm whether the presence of $\operatorname{CD} 69^{+}$ $\mathrm{CD} 4^{+} \mathrm{T}$ cells affects on the allergic diarrhea, anti-CD69 $\mathrm{mAb}$ was administered to the food allergy model for the assessment of diarrhea occurrence as shown in Fig. 4A. Mice sensitized and challenged with OVA (OVA group) started to develop diarrhea from day 4 , while mice sensitized and challenged with OVA plus control IgG treatment (OVA + control IgG group) and mice sensitized and challenged with OVA plus anti-CD69 mAb treatment (OVA+anti-CD69 mAb group) had no diarrhea. On day 6, OVA group reached the highest diarrhea occurrence of $70 \%$, while that of OVA+control IgG group and OVA +anti-CD69 mAb group showed only of an average of $38 \%$ and $13 \%$, respectively. OVA + anti-CD69 $\mathrm{mAb}$ group had significantly lower levels of diarrhea than the other groups with the delay of start of diarrhea $(p<0.05$, OVA + control IgG group compared with OVA + anti-CD69 mAb group, Fig. 4B).

Effect of anti-CD69 mAb treatment on IgE production

Treatment with control IgG or anti-CD69 mAb slightly but significantly decreased IgE level in the sera compared to OVA group. However the difference of IgE level between OVA+control IgG group and OVA+antiCD69 mAb group was not statistically significant 
(Fig. 4C).

Effect of anti-CD69 $\mathrm{mAb}$ treatment on cytokine productions in OVA-induced food allergy

Effects of anti-CD69 mAb treatment on cytokine productions were analyzed in the OVA-induced food allergy model. No significant effects of anti-CD69 mAb treatment on IL-4, IL-5, and IL-13 production were observed in spleen or MLN (Fig. 5A-F). Although only control IgG treatment showed increased production of IFN- $\gamma$ in spleen but not in MLN $(p<0.05$, OVA group compared with OVA+control IgG group, Fig. 5G), totally antiCD69 mAb treatment did not induce any modifications on cytokine producibilities in spleen and MLN.

Effect of anti-CD69 $\mathrm{mAb}$ on $\mathrm{CD} 4^{+} \mathrm{T}$ cell population in OVAinduced food allergy

The effect of anti-CD69 mAb treatment on $\mathrm{CD}^{+}{ }^{+} \mathrm{T}$ cell population was investigated in the food allergy model. OVA + anti-CD $69 \mathrm{mAb}$ group significantly decreased the $\mathrm{CD} 69^{+} \mathrm{CD} 4^{+} \mathrm{T}$ cells in spleen and MLN $(p<0.05$, OVA group compared with OVA+anti-CD69 mAb group, and OVA + control IgG group compared with OVA+ antiCD69 mAb group, Fig. 6A, B).

However, there were not significant differences on cell populations of T-bet ${ }^{+}$, GATA- $3^{+}$, or FoxP $3^{+} \mathrm{CD}^{+}$ $\mathrm{T}$ cells in the spleen and MLN among three groups of OVA, OVA + control IgG, and OVA + anti-CD69 mAb (Fig. $6 \mathrm{C}-\mathrm{H})$.

\section{DISCUSSION}

Our experimental mouse model provided the opportunity to study the effect of cholecalciferol in food allergy. In a previous mouse model study, vitamin $\mathrm{D}_{3}$ was indicated to inhibit asthma-associated inflammatory responses (11). In the present study, we demonstrated significant inhibitory effect of cholecalciferol on a symptom of food allergy when given to mice during allergen challenges.

In our food allergy model, OVA-sensitized and challenged mice developed a typical food allergic reaction, diarrhea, with the increase of $\mathrm{CD}^{+}{ }^{+} \mathrm{T}$ cells expressing CD69, an early activation marker of inflammation (12), slightly in spleen and significantly in MLN. Treatment with cholecalciferol improved the diarrhea with decrease of the $\mathrm{CD} 69^{+} \mathrm{CD} 4^{+} \mathrm{T}$ cell population especially seen in MLN. Therefore, it seemed that the $\mathrm{CD} 69^{+} \mathrm{CD} 4^{+}$ $\mathrm{T}$ cell population could be involved in the occurrence of diarrhea. It was also found that mice which decreased the $\mathrm{CD} 69^{+} \mathrm{CD} 4^{+} \mathrm{T}$ cell population by the treatment with anti-CD69 mAb improved the diarrhea, suggesting the decrease of $\mathrm{CD}_{6} 9^{+} \mathrm{CD} 4^{+} \mathrm{T}$ cells contributed to the down-regulation of food allergic reaction. From these results, thereby, the decreasing effect of cholecalciferol on the $\mathrm{CD}_{6} 9^{+} \mathrm{CD}^{+} \mathrm{T}$ cell population was presumed to elicit the reduction of diarrhea occurrence. However, since it has remained to be clarified how cholecalciferol directly or indirectly was linked to down-regulation of the cell population and diarrhea occurrence in our model, further investigations would be necessary to know the detailed mechanism.

Despite the suppression of allergic diarrhea in chole- calciferol- or anti-CD69 mAb-treated mice, both treatments did not significantly lower serum IgE levels, and had no significant effects on allergen-induced cytokine productions including IL-4, IL-5 and IL-13. We speculate these results might be due to non-IgE mediated association in food allergies (13).

$\mathrm{CD}^{+} \mathrm{FoxP}^{+}$Treg cell populations both in spleen and MLN were not significantly changed by the cholecalciferol treatment, indicating that cholecalciferol was not effective in creating Treg-induced tolerance for reducing diarrhea in our mouse model. This result was also shown elsewhere that vitamin $\mathrm{D}_{3}$ did not affect Treg cells (14). In anti-CD69 mAb treated mice, we did not observe any changes in $\mathrm{FoxP}^{+} \mathrm{CD}^{+}{ }^{+} \mathrm{T}$ cell population. Based on our data, we suggest that neither cholecalciferol treatment nor anti-CD69 $\mathrm{mAb}$ treatment induced Treg-mediated immune tolerance to down-regulate the allergic reaction. Moreover, cholecalciferol treatment to OVA-challenged mice did not affect type 1 helper $\mathrm{T}$ cells (Th1) specific transcription factor T-bet, and type 2 helper $\mathrm{T}$ cells (Th2) specific transcription factor GATA3. Additionally, anti-CD69 mAb treatment also did not change Th1/Th2 specific transcription factors. These results mean that Th1/Th2 specific transcriptions might not be crucial factors in the reduction of diarrhea in our food allergy model.

Based on the review by Kimura et al., there has been no anti-CD69 mAb treatment model reported on food allergy to date (15). We used two-day treatment of anti-CD69 mAb with $50 \mu \mathrm{g} /$ mouse which was lower dose than other asthma mouse models (16), and the dose was similar to the asthma model established by Wang et al. (17). As for our experiment, we compared the effects of control IgG and anti-CD69 $\mathrm{mAb}$ in the assessment of diarrhea occurrence. Unexpectedly, the slight reduction of allergic diarrhea was observed in the mice treated with control IgG corresponding to the IgG of anti-CD69 mAb. We speculate it might be due to the ratio change of IgE and IgG during the allergen challenge, as it has been reported that reduction of allergic reaction was mostly induced with the increase of $\operatorname{IgG}$ (18). In our experiment, such the unexpected factor of IgG antibodies seemed to be appeared. However, because the influence of the IgG antibodies was added equally to both groups of control IgG and anti-CD69 mAb treatment, it could be suggested that the decrease of $\mathrm{CD} 69^{+}$ $\mathrm{CD}^{+} \mathrm{T}$ cells resulted in the diarrhea reduction with considering the influence of IgG injection.

In terms of immune modification effects of cholecalciferol and anti-CD69 mAb, we did not observe any significant reductions of IgE levels in sera and cytokine producibilities in spleen and MLN when the mice were treated with cholecalciferol or anti-CD69 mAb, whereas the diarrhea was improved in both experiments. Future studies will need to investigate the mechanism how the decrease of $\mathrm{CD} 69^{+} \mathrm{CD} 4^{+} \mathrm{T}$ cell population resulted in the reduction of diarrhea occurrence.

On the other hand, it has been reported that $1 \alpha, 25-$ dihydroxyvitamin $\mathrm{D}_{3}$, which was activated form of cholecalciferol, had protective effects against intestinal 
tissue barrier disruption and high permeability in the intestinal mucosa induced by exogenous stimulants (19-21). Therefore, by such protective effect, vitamin $\mathrm{D}_{3}$ seems likely to maintain integrity of mucosal barrier, leading to attenuation of allergen exposure to intestinal tissue and reduction of allergen permeability in intestinal mucosa. As a consequence, the migration of $\mathrm{CD}^{+} \mathrm{CD}^{+} 9^{+} \mathrm{T}$ cells into the local inflamed site might be down-regulated in the presence of cholecalciferol, implying that the regulation is presumed to be one of the mechanisms underlying the inhibitory effect of cholecalciferol on food allergic reaction.

We also suggest another possible inhibitory effect of cholecalciferol on the food allergy symptom through a different type of cell such as mast cells. Mast cells are well known to be required in allergen-induced diarrhea (22-24). As it has been reported that vitamin $\mathrm{D}_{3}$ suppressed the mast cell activation $(25,26)$, we presume that cholecalciferol might also possibly control the allergic diarrhea through the suppressive effect on mast cells in addition to that on $\mathrm{CD} 4^{+} \mathrm{T}$ cells in our model. In addition, several studies reported that mast cells could express CD69 on the cell surface in some situations (27, 28). Actually, Gaudenzio et al. demonstrated that CD69 expression on the activated mast cells was induced in the presence of allergen with immune cytokines (28). In our study, therefore, anti-CD69 mAb treatment might affect the cell number or function of mast cells for reducing the diarrhea occurrence. The possible involvement of the mast cells in our food allergy model also has to be further investigated in future studies.

In current study, it was suggested that cholecalciferol treatment exhibited reduction in food allergy symptom of diarrhea with the decrease of $\mathrm{CD} 69^{+} \mathrm{CD} 4^{+} \mathrm{T}$ cells. Our data could provide a novel possibility of cholecalciferol administration for controlling a symptom of food allergy.

\section{Acknowledgments}

The authors thank our lab members, Ms. Kodama, Mr. Takei and Mr. Yoshikawa for their technical support and animal care.

\section{Author contributions}

E.Z performed the experiments, analyzed the data and wrote the manuscript. S.A. analyzed the data and wrote the manuscript. T.O. contributed in the interpretation of the results. N.Y. analyzed the data and wrote the manuscript. J.Y. interpreted the results, wrote the manuscript and supervised the entire study.

\section{Funding sources}

This study was supported by the research budget of Tokyo Women's Medical University and the Japanese Government Scholarship by the Ministry of Education, Culture, Sports, Science and Technology (MEXT) to international students (140696 to E.Z.).

\section{Supporting Information}

Supplemental online material is available on J-STAGE.

\section{REFERENCES}

1) Sicherer SH, Sampson HA. 2014. Food allergy: Epidemiology, pathogenesis, diagnosis, and treatment. J Allergy Clin Immunol 133: 291-307.

2) Liu AH, Jaramillo R, Sicherer SH, Wood RA, Bock SA, Burks AW, Massing M, Cohn RD, Zeldin DC. 2010. National prevalence and risk factors for food allergy and relationship to asthma: results from the National Health and Nutrition Examination Survey 2005-2006. J Allergy Clin Immunol 126: 798-806.

3) Jones SM, Burks AW, Dupont C. 2014. State of the art on food allergen immunotherapy: oral, sublingual, and epicutaneous. J Allergy Clin Immunol 133: 318-323.

4) Lemire JM. 1995. Immunomodulatory actions of 1,25-dihydroxyvitamin D3. J Steroid Biochem Mol Biol 53: 599.

5) Allen KJ, Koplin JJ, Ponsonby AL, Gurrin LC, Wake M, Vuillermin P, Martin P, Matheson M, Lowe A, Robinson M, Tey D, Osborne NJ, Dang T, Tina Tan HT, Thiele L, Anderson D, Czech H, Sanjeevan J, Zurzolo G, Dwyer T, Tang ML, Hill D, Dharmage SC. 2013. Vitamin D insufficiency is associated with challenge-proven food allergy in infants. J Allergy Clin Immunol 131: 1109-1116.

6) Baek JH, Shin YH, Chung IH, Kim HJ, Yoo EG, Yoon JW, Jee HM, Chang YE, Han MY. 2014. The link between serum vitamin D level, sensitization to food allergens, and the severity of atopic dermatitis in infancy. J Pediatr 165: 849-854.

7) Vassallo MF, Camargo CA Jr. 2010. Potential mechanisms for the hypothesized link between sunshine, vitamin D, and food allergy in children. J Allergy Clin Immunol 126: 217-222.

8) Norizoe C, Akiyama N, Segawa T, Tachimoto H, Mezawa H, Ida H, Urashima M. 2014. Increased food allergy and vitamin D: randomized, double-blind, placebo- controlled trial. Pediatr Int 56: 6-12.

9) Litonjua AA. 2012. Vitamin D deficiency as a risk factor for childhood allergic disease and asthma. Curr Opin Allergy Clin Immunol 12: 179-185.

10) Holick MF. 2007. Vitamin D deficiency. N Eng J Med 357: 266-281.

11) Topilski I, Flaishon L, Naveh Y, Harmelin A, Levo Y, Shachar I. 2004. The anti-inflammatory effects of 1,25-dihydroxyvitamin D3 on Th2 cells in vivo are due in part to the control of integrin-mediated Tymphocyte homing. Eur J Immunol 34: 1068-1076.

12) Hasegawa A, Iwamura C, Kitajima M, Hashimoto K, Otsuyama K, Ogino H, Nakayama T, Shirai M. 2013. Crucial role for CD69 in the pathogenesis of dextran sulphate sodium-induced colitis. PLoS One 8: e65494.

13) Kulis M, Gorentla B, Burks AW, Zhong XP. 2013. Type B CpG oligodeoxynucleotides induce Th1 responses to peanut antigens: modulation of sensitization and utility in a truncated immunotherapy regimen in mice. Mol Nutr Food Res 57: 906-915.

14) Poole A, Song Y, Brown H, Hart PH, Zhang GB. 2018. Cellular and molecular mechanisms of vitamin D in food allergy. J Cell Mol Med 22: 3270-3277.

15) Kimura MY, Hayashizaki K, Tokoyoda K, Takamura S, Motohashi S, Nakayama T. 2017. Crucial role for CD69 in allergic inflammatory responses: CD69-Myl9 system in the pathogenesis of airway inflammation. Immunul Rev 278: 87-100.

16) Miki-Hosokawa T, Hasegawa A, Iwamura C, Shinoda K, Tofukuji S, Watanabe Y, Hosokawa H, Motohashi 
S, Hashimoto K, Shirai M, Yamashita M, Nakayama T. 2009. CD69 controls the pathogenesis of allergic airway inflammation. J Immunol 183: 8203-8215.

17) Wang HY, Dai Y, Wang JL, Yang XY, Jiang XG. 2015. Anti-CD69 monoclonal antibody treatment inhibits airway inflammation in a mouse model of asthma. J Zhejiang Univ Sci B 16: 622-631.

18) Wright BL, Kulis M, Orgel KA, Burks AW, Dawson P, Henning AK, Jones SM, Wood RA, Sicherer SH, Lindblad RW, Stablein D, Leung DY, Vickery BP, Sampson HA. 2016. Consortium of Food Allergy Research. Component-resolved analysis of $\operatorname{IgA}$, IgE, and IgG4 during egg OIT identifies markers associated with sustained unresponsiveness. Allergy 71: 1552-1560.

19) Kong J, Zhang Z, Musch MW, Ning G, Sun J, Hart J, Bissonnatte M, Li YC. 2008. Novel role of the vitamin D receptor in maintaining the integrity of the intestinal mucosal barrier. Am J Physiol Gastrointest Liver Physiol 294: 208-216.

20) Chen SW, Wang PY, Zhu J, Chen GW, Zhang JL, Chen ZY, Zuo S, Liu YC, Pan YS. 2015. Protective effect of 1,25-dihydroxyvitamin D3 on lipopolysaccharideinduced intestinal epithelial tight junction injury in caco-2 cell monolayers. Inflammation 38: 375-383.

21) Chen SW, Ma YY, Zhu J, Zuo S, Zhang JL, Chen ZY, Chen GW, Wang X, Pan YS, Liu YC, Wang PY. 2015. Protective effect of 1,25-dihydroxyvitamin D3 on ethanol-induced intestinal barrier injury both in vitro and in vivo. Toxicol Lett 237: 79-88.

22) Reber LL, Sibilano R, Mukai K, Galli SJ. 2015. Potential effector and immunoregulatory functions of mast cells in mucosal immunity. Mucosal Immunol 8: 444-463.

23) Wang M, Takeda K, Shiraishi Y, Okamoto M, Dakhama A, Joetham A, Gelfand EW. 2010. Peanut-induced intestinal allergy is mediated through a mast cell-IgEFcepsilonRI-IL-13 pathway. J Allergy Clin Immunol 126: 306-316.

24) Brandt EB, Strait RT, Hershko D, Wang Q, Muntel EE, Scribner TA, Zimmermann N, Finkelman FD, Rothenberg ME. 2003. Mast cells are required for experimental oral allergen-induced diarrhea. J Clin Invest 112 : 1666-1677.

25) Yip KH, Kolesnikoff N, Yu C, Hauschild N, Taing H, Biggs L, Goltzman D, Gregory PA, Anderson PH, Samuel MS, Galli SJ, Lopez AF, Grimbaldeston MA. 2014. Mechanisms of vitamin D3 metabolite repression of IgE-dependent mast cell activation. J Allergy Clin Immunol 133: 1356-1364.

26) Liu ZQ, Li XX, Qiu SQ, Yu Y, Li MG, Yang LT, Li LJ, Wang S, Zheng PY, Liu ZG, Yang PC. 2017. Vitamin D contributes to mast cell stabilization. Allergy 72: 1184-1192.

27) Valent P, Schernthaner GH, Sperr WR, Fritsch G, Agis H, Willheim M, Bühring HJ, Orfao A, Escribano L. 2001. Variable expression of activation-linked surface antigens on human mast cells in health and disease. Immunol Rev 179: $74-81$.

28) Gaudenzio N, Espagnolle N, Mars LT, Liblau R, Valitutti S, Espinosa E. 2009. Cell-cell cooperation at the T helper cell/mast cell immunological synapse. Blood 114 : 4979-4988. 